\title{
Endoscopic endonasal management of cerebrospinal fluid rhinorrhea after anterior clinoidectomy for aneurysm surgery: changing the paradigm of complication management
}

\author{
Endoscopia endonasal no tratamento da fístula liquórica após clinoidectomia anterior na \\ cirurgia de aneurisma: mudando o paradigma no manejo desta complicação \\ Andre Beer-Furlan 1,2, Leonardo Balsalobre ${ }^{1,2,3}$, Eduardo de Arnaldo Silva Vellutini',2, Aldo Cassol Stamm ${ }^{1,2,3}$, \\ Felix Hendrik Pahl1,2, Andre Felix Gentil ${ }^{4}$
}

\begin{abstract}
Resection of the anterior clinoid process results in the creation of the clinoid space, an important surgical step in the exposure and clipping of clinoidal and supraclinoidal internal carotid artery aneurysms. Cerebrospinal fluid rhinorrhea is an undesired and potentially serious complication. Conservative measures may be unsuccesful, and there is no consensus on the most appropriate surgical treatment. Two patients with persistent transclinoidal CSF rhinorrhea after aneurysm surgery were successfully treated with a combined endoscopic transnasal/transeptal binostril approach using a fat graft and ipsilateral mucosal nasal septal flap. Anatomical considerations and details of the surgical technique employed are discussed, and a management plan is proposed.
\end{abstract}

Keywords: aneurysm; cerebrospinal fluid leak; endoscopy.

\section{RESUMO}

A ressecção da clinóide anterior resulta na criação do espaço clinoideo, um passo cirúrgico importante na exposição e clipagem de aneurismas dos segmentos clinoideo e supraclinoideo da artéria carótida interna. Fístula liquórica é uma das complicaçoes mais indesejadas e é potencialmente grave. 0 manejo com medidas conservadoras pode ser bem sucedido, e não há consenso sobre o tratamento cirúrgico mais adequado. Dois pacientes com rinorréia persistente secundária a fistula liquórica transclinoidal após cirurgia de aneurisma foram tratados com sucesso por uma abordagem endoscópica combinada transnasal/transseptal binostril usando um enxerto de gordura e retalho de mucosa naso-septal ipsilateral. Considerações anatômicas e detalhes da técnica cirúrgica empregada são discutidos, e um plano de manejo destes tipo de fistula líquorica é proposto.

Palavras-chave: aneurisma; vazamento de líquido cefalorraquidiano; endoscopia.

Resection of the anterior clinoid process (ACP) is an importat surgical step in the exposure of the clinoid space, allowing the microsurgical clipping of clinoidal and supraclinoidal internal carotid artery (ICA) aneurysms ${ }^{1}$. Complications related to anterior clinoidectomy in modern surgical series include damage to the optic nerve with resulting visual field defects, oculomotor palsy, accidental intraoperative aneurysm rupture, and postoperative cerebrospinal fluid (CSF) rhinorrhea ${ }^{2}$. This latter complication is more prone to occur because dural incisions required for the removal of the ACP prevent the watertight closure of the dura mater. In cases where the optic strut is pneumatized (4 to $29.3 \%)^{3,4}$, anterior clinoidectomy creates a communication between the subarachnoid space and the

${ }^{1}$ Centro de Base de Crânio de São Paulo, São Paulo SP, Brasil;

${ }^{2}$ DFVneuro, São Paulo SP, Brasil;

${ }^{3}$ Hospital Professor Edmundo Vasconcelos, Centro de Otorrino e Fonoaudiologia, São Paulo SP, Brasil;

${ }^{4}$ Hospital Israelita Albert Einstein, São Paulo SP, Brasil.

Correspondence:André Beer-Furlan; Rua Dona Adma Jafet, 74 / cj.121; 05018-000 São Paulo SP; Brasil. E-mail: beerfurlan@uol.com.br

Conflict of interest: There is no conflict of interest to declare.

Received 08 January 2016; Received in final form 26 April 2016; Accepted 09 May 2016. 
sphenoid sinus, making defect closure particularly challenging, despite the use of different materials and techniques ${ }^{5}$. Postoperative persistent CSF rhinorrhea is still a frequent and undesirable complication of paraclinoid aneurysm surgery, with the potential to cause meningitis, tension pneumocephalus, the need for repeated surgical interventions, and prolonged hospitalization.

This report describes the successful management of CSF rhinorrhea after anterior clinoidectomy with an endoscopic mucosal nasal septal flap and fat graft ${ }^{6}$, proposing a management plan and a change in the paradigm on how this complication is treated.

\section{Anatomical considerations of the ACP}

From a superior view, the ACP appears as a triangular mass with its base located in the medial part of the posterior border of the lesser sphenoid wing, and its tip projecting medial-posteriorly. Anteriorly, the base of the ACP continues with the medial end of the sphenoid ridge. Medially, the base attaches to the body of the sphenoid bone by the posterior and anterior roots of the lesser sphenoid wing. The anterior root forms the roof of the optic canal. The posterior root (the optic strut) extends from the lower margin of the base of the ACP to the body of the sphenoid bone, forming the anterior part of the lateral and inferior walls of the optic canal, and separating the optic canal from the superior orbital fissure (Figure 1).

From an endonasal transsphenoidal perspective, the optic strut corresponds to the lateral optic-carotid recess (OCR), the main route for pneumatization of the ACP (Figure 2). Therefore, localizing the defect when repairing a CSF fistula via an endoscopic endonasal approach is relatively easy.

\section{Intraoperative closure of ACP defects after anterior clinoidectomy}

Preoperative planning for paraclinoid aneurysm surgery routinely includes a head CT scan with bone window to study the anatomy of the ACP (Figure 3). If the optic strut is pneumatized, special care should be taken when closing the dural defect to avoid CSF fistula. Also, top-down infraction of the sphenoid sinus mucosa should be avoided during ACP removal and optic strut drilling with the use of a diamond burr. After the aneurysm is clipped, a muscle graft is plugged into the bone defect and secured in place with fibrin glue.

\section{Endoscopic endonasal treatment of CSF fistula}

The technique for endoscopic endonasal surgical repair of the CSF leak corresponds to a variation of the Combined Endoscopic Transnasal/Transeptal Binostril Approach ${ }^{7}$. The first step is a caudal septal incision, followed by bilateral subperichondrial dissection and cartilaginous/bony septum removal, keeping the septum cartilage with an "L" shape to prevent nose deformity.
Then, a pedicled nasoseptal flap is harvested ipsilateral to the anterior clinoidectomy and CSF fistula (contralateral to the septal incision) and placed in the nasopharynx. Next, unilateral opening of the anterior sphenoid sinus wall is done with a micro-Kerrison punch, and the sphenoid rostrum is drilled. The sinus mucosa that lines the bone defect region is reflected carefully, exposing the OCR and allowing for visual confirmation of the CSF fistula. Finally, a small fat graft removed from the thigh or abdomen is plugged into the bone defect and the nasal septal flap is positioned to cover the entire region. Spongostan
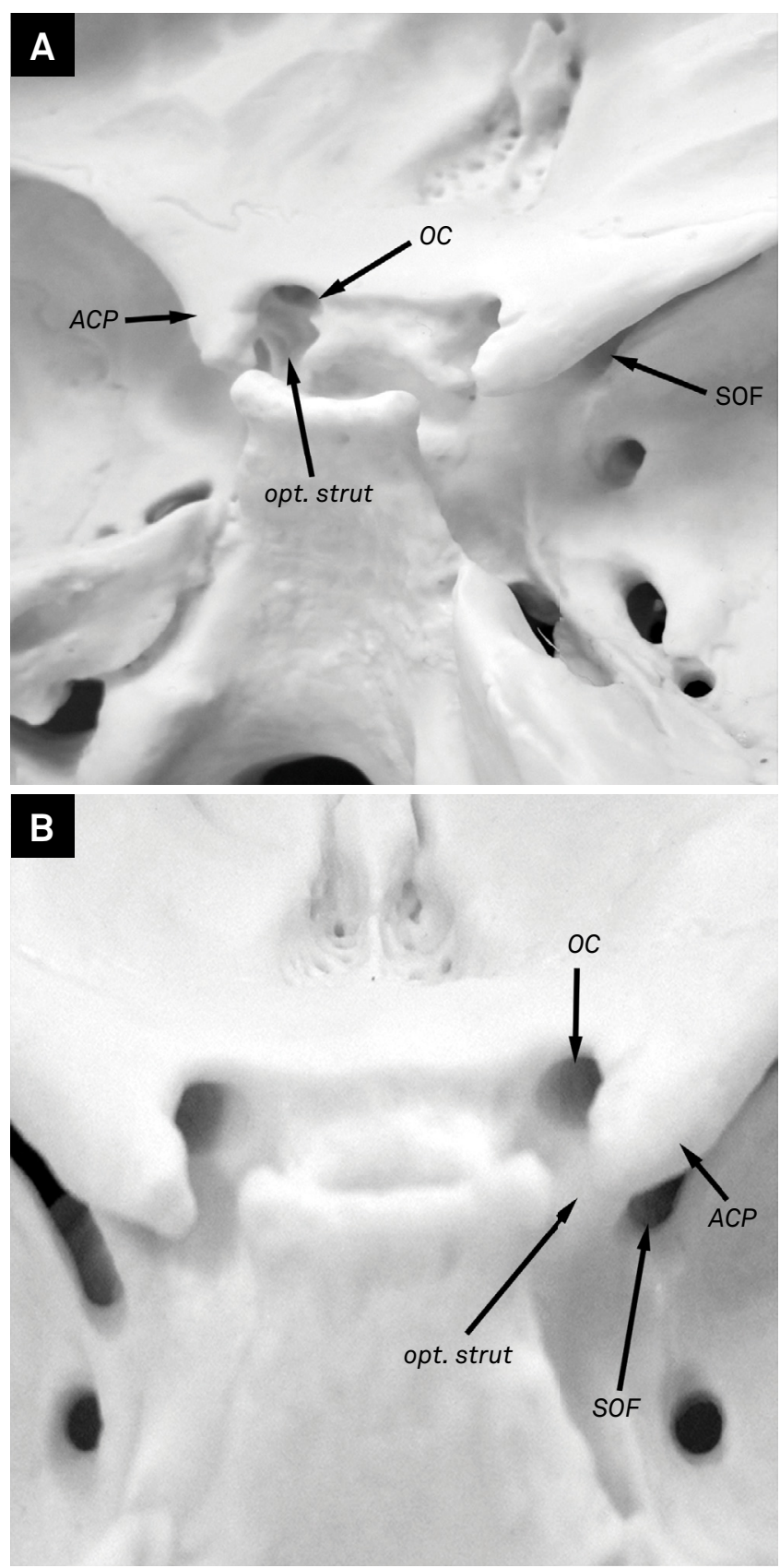

ACP: anterior clinoid process; OC: optic canal; opt.strut: optic strut; SOF: superior orbital fissure.

Figure 1. Bone anatomy of the anterior clinoid process region. (A) Lateral anterior view; (B) Postero-anterior view. 

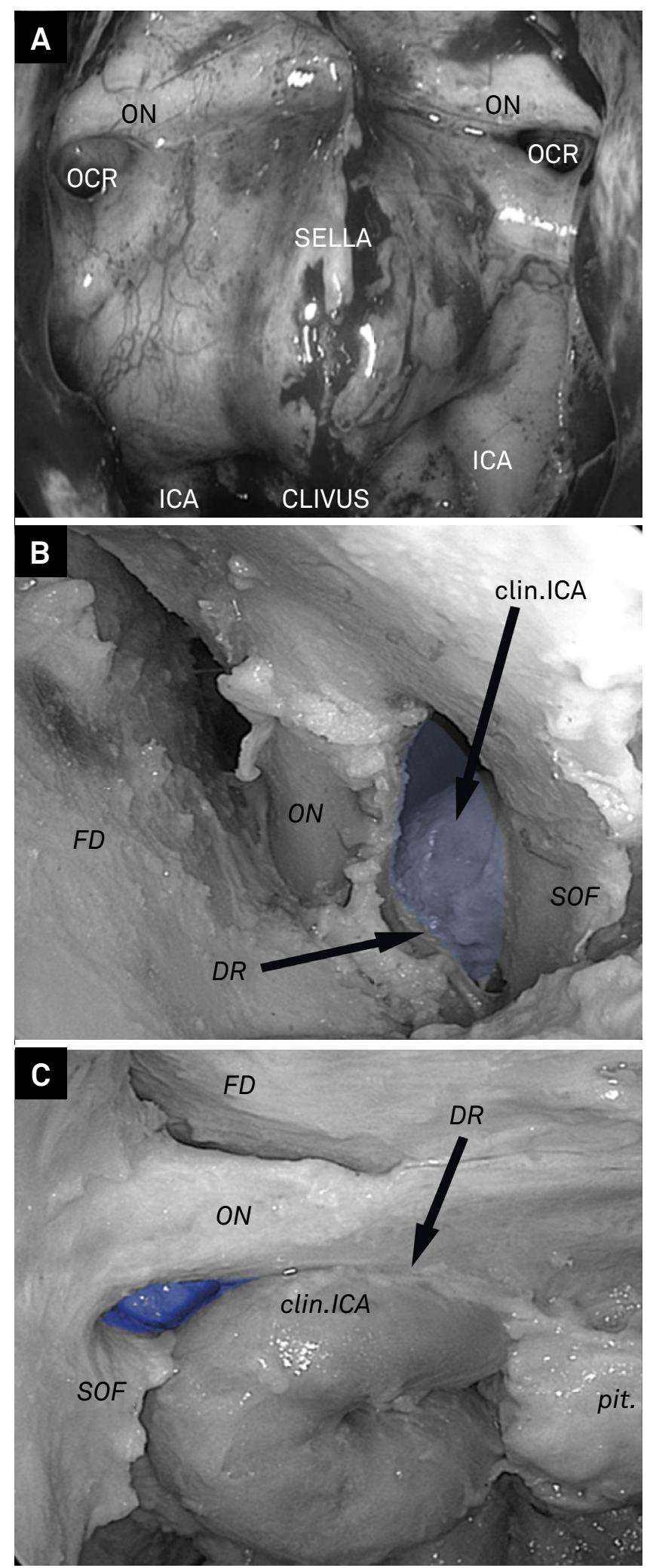

clin.ICA: clinoid segment of the internal carotid artery; DR: distal dural ring; FD: frontal dura mater; ICA: internal carotid artery; ON: optic nerve; OCR: lateral opticocarotid recess; pit.: pituitary gland; SOF: superior orbital fissure; SELLA: sella; CLIVUS: clivus;

Figure 2. (A) Intraoperative image of a well pneumatized optic strut. (B) Transcranial anatomical cadaveric dissection after a right side epidural anterior clinoidectomy and removal of the optic strut, exposing the clinoid space and the clinoid segment of the ICA. (C) The transnasal perspective the same anatomy where the location of the optic strut (blue) is visualized.

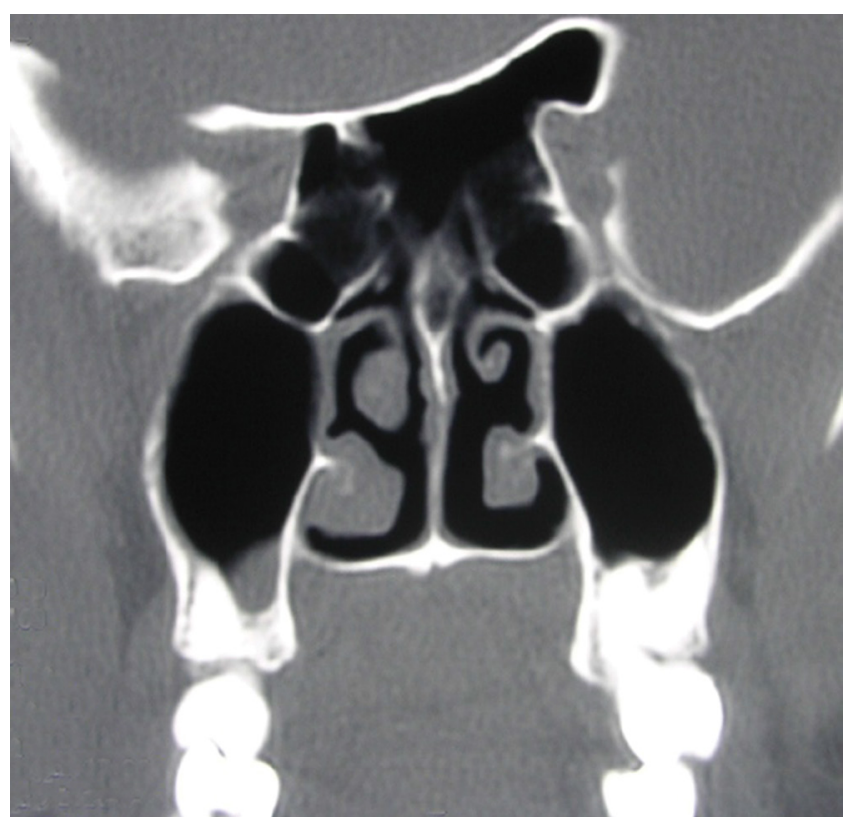

CT: computed tomography; ACP: anterior clinoid process.

Figure 3. Head CT scan. Preoperative coronal images showing a pneumatized optic strut and ACP.

powder (Ethicon; Somerville, NJ) and Gelfoam (Pfizer; New York, NY) are layered directly over the flap to hold it in place, followed by anterior nasal packing.

Patients are kept at bed rest for 24 hours after surgery. Anterior nasal packing is removed on postoperative day 2. With confirmation that the CSF leak has been resolved, patients are discharged home on day 3.

\section{Case illustration}

\section{Case 1}

A 43-year-old woman with a family history of brain aneurysms was diagnosed with an incidental left incidental ophthalmic ICA aneurysm. She underwent elective surgery, with a Dolenc approach and epidural anterior clinoidectomy (Figure 4). The aneurysm was successfully clipped and the skull base reconstructed uneventfully. A routine head computed tomography $(\mathrm{CT})$ scan on postoperative day 1 revealed no complications.

On postoperative day 3 , the patient developed a CSF rhinorrhea through the left nostril. A new CT scan did not show radiological changes. Conservative treatment was started, with a lumbar drain, bed rest, and acetazolamide. After 3 days, a new CT scan did not show increased pneumocephalus.

After 5 days of conservative treatment, CSF rhinorrhea persisted if the lumbar drain was closed. Decision was made to perform endoscopic endonasal surgery and an ipsilateral mucosal nasal septal flap was used to reconstruct the skull base as previously described (Figure 5). CSF rhinorrhea did not recur, and the patient was discharged home 3 days after. 

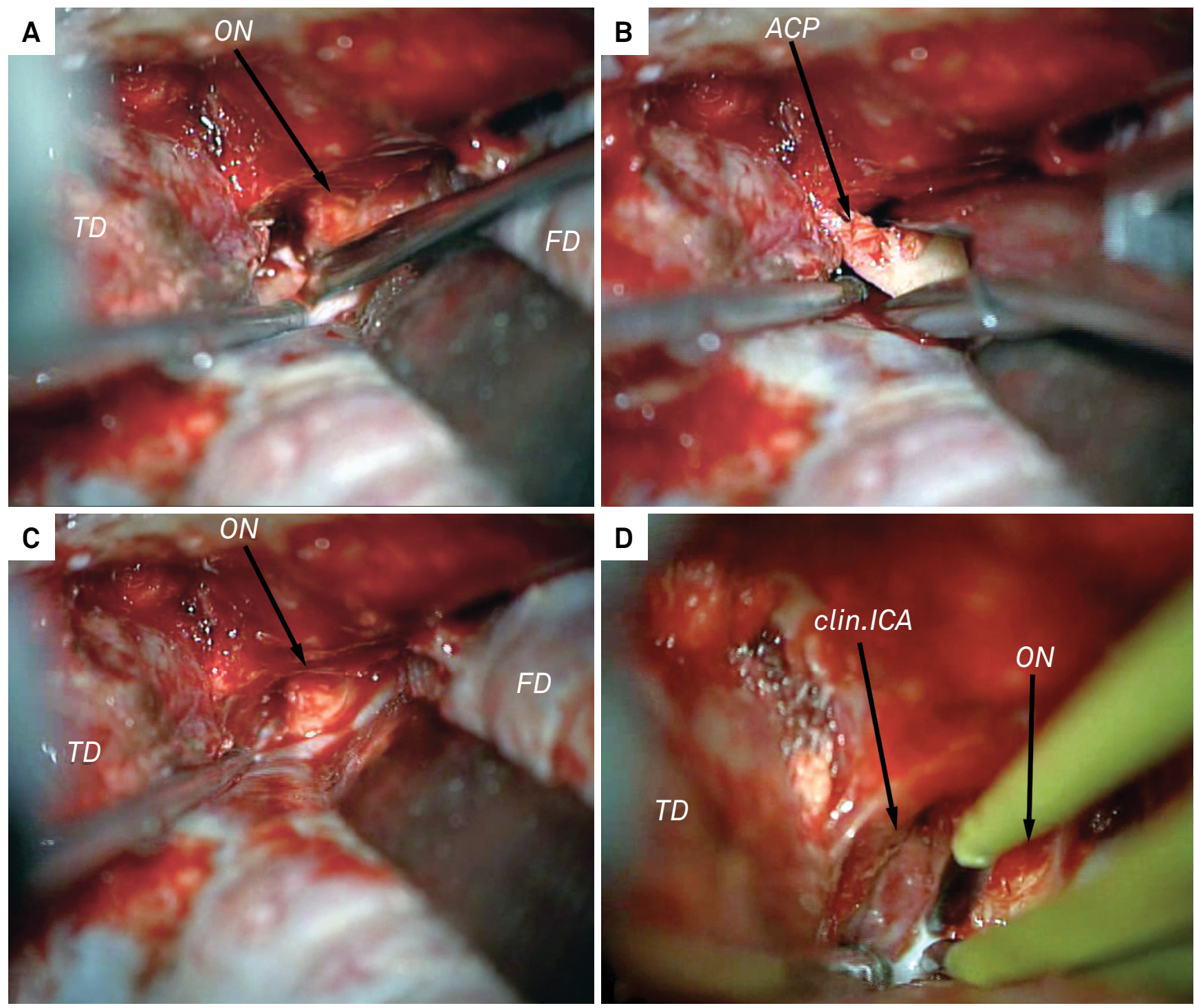

ACP: anterior clinoid process; clin.ICA: clinoid segment of the internal carotid artery; FD: frontal dura mater; ON: optic nerve; TD: temporal dura mater.

Figure 4. Dolenc approach (left side) for an ophthalmic segment ICA aneurysm. (A) Optic nerve decompression and drilling of the base of the ACP. (B) Removal of the ACP. (C) Controlling the bleeding of the cavernous sinus. (D) Exposure of the clinoid segment of the ICA.

\section{Case 2}

A 50-year-old woman was diagnosed with a right ophthalmic ICA aneurysm after radiological investigation due to unrelated persistent headaches. She underwent elective surgical clipping of the aneurysm with a Dolenc approach combined with epidural anterior clinoidectomy, and the skull base was reconstructed uneventfully. A head CT scan on postoperative day 1 did not show complications.

Right nostril CSF rhinorrhea started on postoperative day 2 , and a head CT scan did not reveal any changes. As in the previous case, conservative measures were started, including a lumbar drain, bed rest, and acetazolamide.

On postoperative day 5 , the patient complained of worsening headache and a new head CT scan demonstrated significant increase in pneumocephalus (Figure 6). An endoscopic endonasal approach was performed and an ipsilateral mucosal nasal septal flap was used to reconstruct the skull base (Figure 7). The patient was discharged home without symptoms 3 days after the procedure.

\section{DISCUSSION}

Different techniques for anterior clinoidectomy have been proposed in the literature. Initially reported as an intradural procedure, the resection of the ACP has also been described as an extradural resection, intradural resection, hybrid extra/intradural resection, fracture removal, drilling removal, and ultrasonic. Although each has its advantages and disadvantages, there is still no consensus on the best method to safely remove the ACP and avoid CSF rhinorrhea $\mathrm{a}^{8,9,10,11,12,13,1,1,1,1,1,17}$. Further, there is even less literature on how to proceed when this worrisome complication does occur. Previous reports of endoscopic endonasal management 

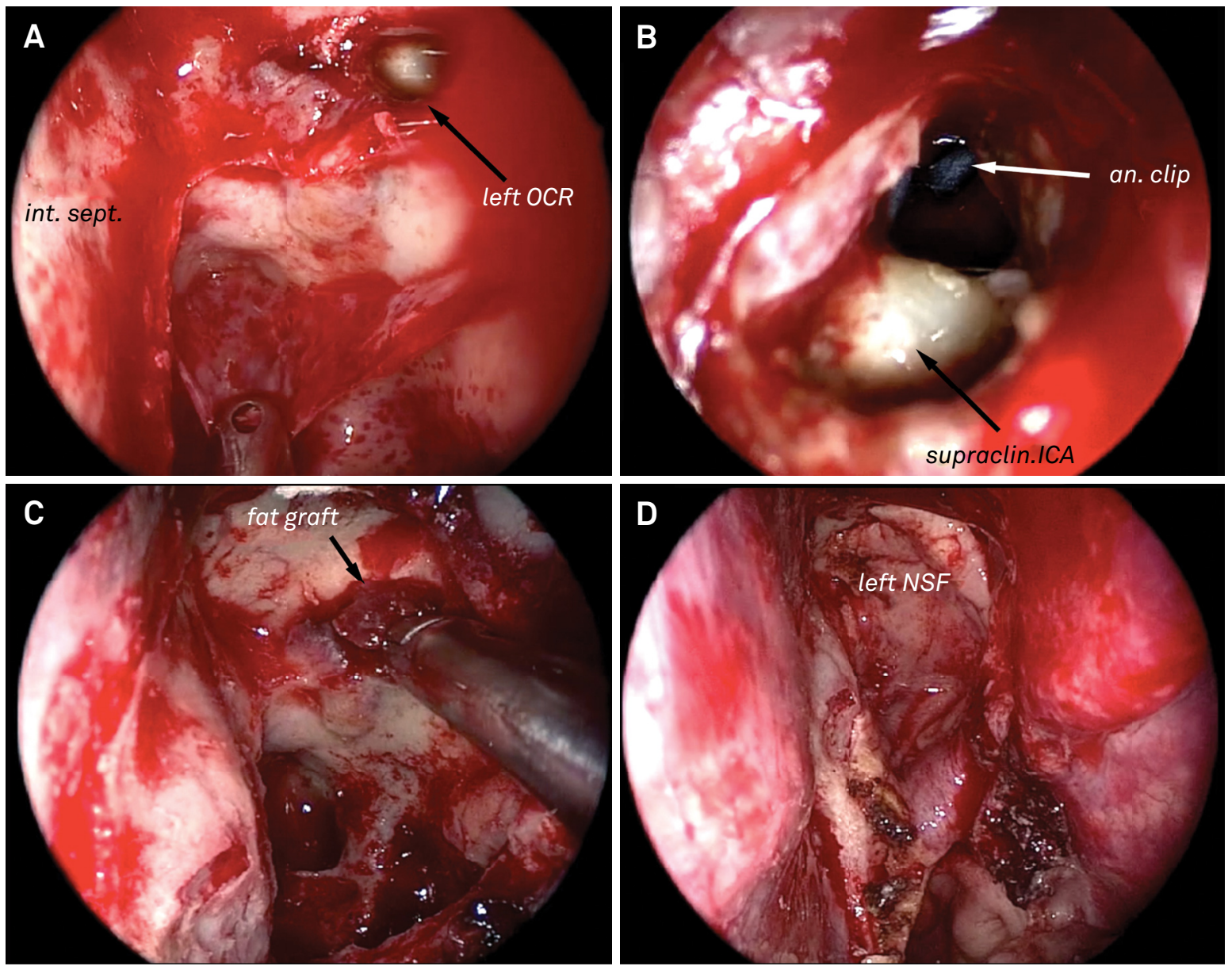

An.clip: aneurysm clip; int.sept.: intersinusal septum; NSF: nasal septal flap; OCR: lateral opticocarotid recess; supraclin.ICA: supraclinoid segment of the internal carotid artery.

Figure 5. Endoscopic endonasal approach for CSF leak repair after a left anterior clinoidectomy. (A) Unilateral sphenoidotomy with removal of the mucosa overlying the sphenoid sinus. (B) The aneurysm clip and the supraclinoid segment of the ICA are visualized in detail through the lateral OCR / optic strut. (C) Fat graft plugged into the bone defect. (D) Left mucosal nasal septal flap covering the bone surface of the left sphenoid sinus.

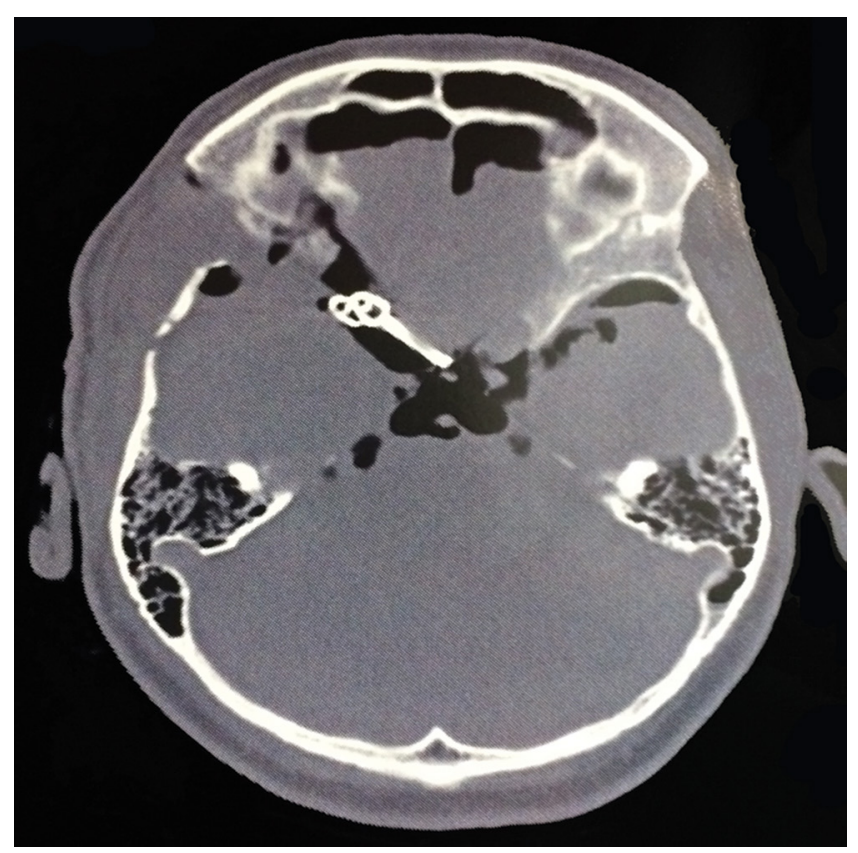

Figure 6. Head computed tomography scan. Postoperative axial images showing the increased pneumocephalus and the aneurysm clips. of this type of CSF fistula mainly described the use of free grafts $^{18,19}$, but the use of nasal septal mucosal flaps has not been objectively proposed.

Greater interaction between the fields of neurosurgery and otolaryngology, driven mainly by the multidisciplinary treatment of pituitary and skull base tumors, has allowed for techniques attuned in one specialty to be tested and proven useful in complementary ways. Our proposal is a good example of this tendency: creating an endoscopic nasal septal mucosal flap, a common otolaryngologic endoscopic procedure, can be an effective surgical treatment for a complication derived from a vascular neurosurgical procedure.

Conservative measures such as bed rest, lumbar drain, and acetazolamide should continue to be advocated because low-flow fistulas can resolve spontaneously, depending on the degree of failure presented by the graft used for closure of the optic strut during the aneurysm clipping procedure. Sequential head CT scans are helpful in deciding whether to maintain conservative treatment or opt for direct surgical repair, as late occurring or progressively increasing 

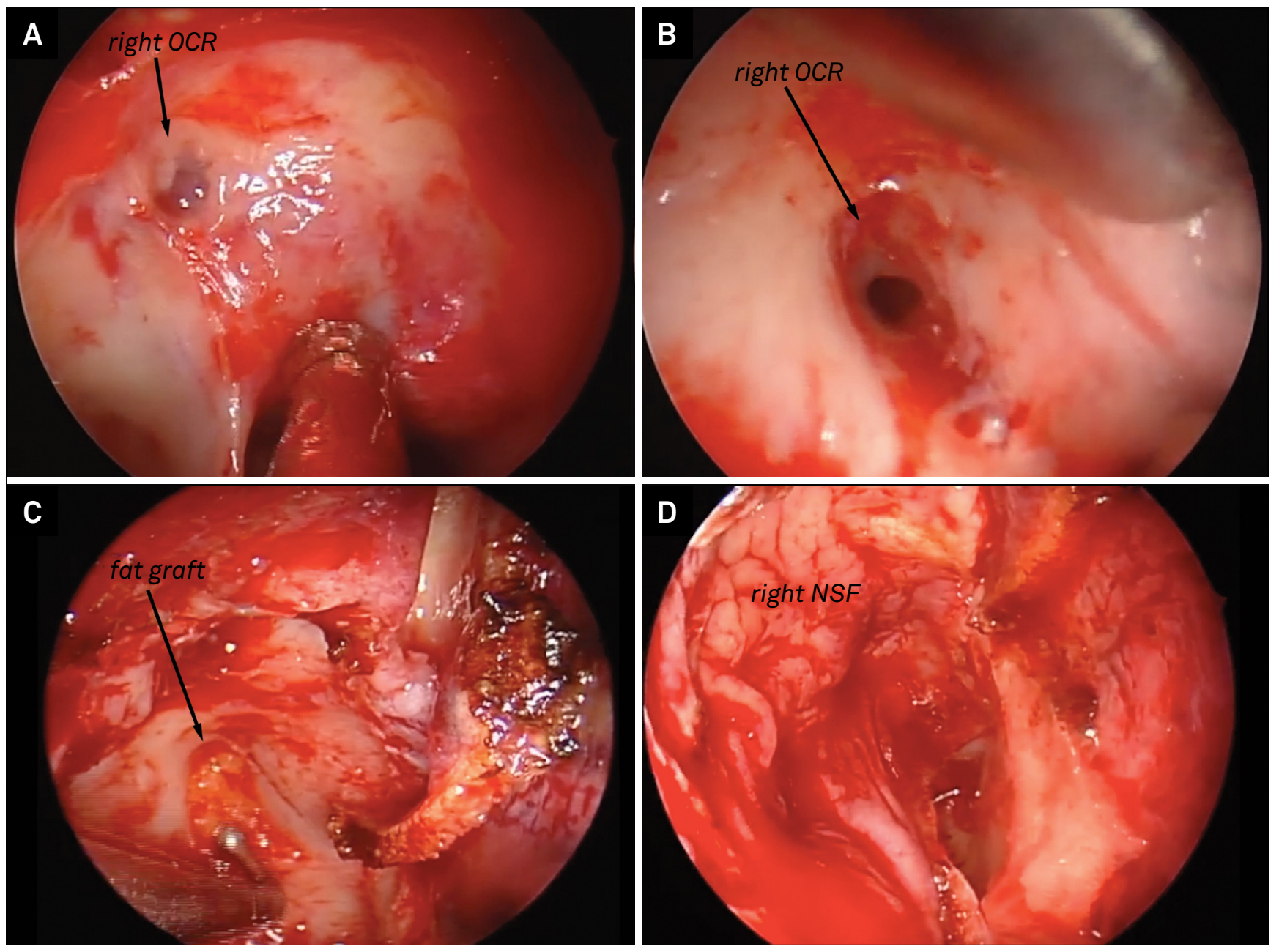

NSF: nasal septal flap; OCR: lateral opticocarotid recess.

Figure 7. Endoscopic endonasal approach for CSF leak repair after a right anterior clinoidectomy. (A) Right sphenoid sinus where part of the sella and the left lateral OCR are visualized. (B) Bone defect seen in detail. (C) Fat graft plugged into the bone defect. (D) Right mucosal nasal septal flap covering the bone surface of the right sphenoid sinus.

pneumocephalus indicate high-flow fistulas that will not resolve conservatively (Figure 8).

The classical neurosurgical management of postoperative persistent CSF fistula has been re-operation with opening of the previous craniotomy and redoing reconstruction over the optic strut. Transcranial reoperation techniques are actually repetitions of the same alternatives that can be used during the aneurysm surgery, including packing with wax or methylmethacrylate, packing with fat and applying fibrin glue, rotation of a vascularized pericranial flap over the defect, associated with diversion of CSF through a lumbar drain during the first postoperative days to help the healing process ${ }^{5}$.

Our proposal for the endoscopic endonasal treatment with a fat graft and mucosal nasal septal flap is a change in the paradigm on the way neurosurgeons manage this type of complication after aneurysm surgery. The Combined Endoscopic Transnasal/Transeptal Binostril Approach technique provides the advantages of allowing two surgeons to manipulate surgical instruments simultaneously; a robust

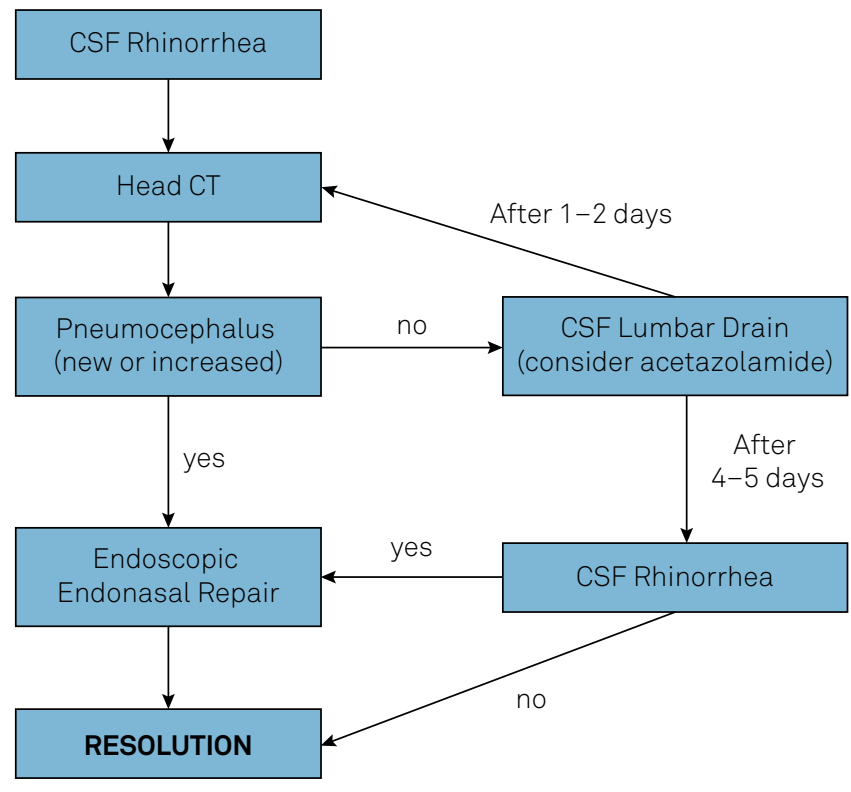

Figure 8. Management plan for CSF rhinorrhea after anterior clinoidectomy in aneurysm surgery. 
pediculated tissue to help in the closure of the skull base defect; and preservation of one side of the nasal septum mucosa, avoiding nasal septal perforation and nasal crusting on one side of the nasal cavity. The endonasal repair has shown to be effective in resolving CSF rhinorrhea after anterior clinoidectomy when conservative measures have failed. Both reported cases give a clear example that this technique is safe and relatively simple when neurosurgeons work in conjunction with otolaryngologists. It has the great advantage of avoiding reopening the craniotomy, and since there is no need for a postoperative lumbar drain, it also reduces hospitalization and patient discomfort.

\section{References}

1. Evans JJ, Hwang YS, Lee JH. Pre- versus post-anterior clinoidectomy measurements of the optic nerve, internal carotid artery, and opticocarotid triangle: a cadaveric morphometric study. Neurosurgery. 2000;46(4):1018-21.

2. Beretta F, Andaluz N, Zuccarello M. Aneurysms of the ophthalmic (C6) segment of the internal carotid artery: treatment options and strategies based on a clinical series. J Neurosurg Sci. 2004;48(4):149-56

3. Abuzayed B, Tanriover N, Biceroglu H, Yuksel O, Tanriover O, Albayram $S$ et al. Pneumatization degree of the anterior clinoid process: a new classification. Neurosurg Rev. 2010;33(3):367-73. doi:10.1007/s10143-010-0255-8

4. Mikami T, Minamida Y, Koyanagi I, Baba T, Houkin K. Anatomical variations in pneumatization of the anterior clinoid process. J Neurosurg. 2007;106(1):170-4. doi:10.3171/jns.2007.106.1.170

5. Chi JH, Sughrue M, Kunwar S, Lawton MT. The "yo-yo" technique to prevent cerebrospinal fluid rhinorrhea after anterior clinoidectomy for proximal internal carotid artery aneurysms. Neurosurgery. 2006;59(1 Suppl 1):ONS101-7.

6. Hadad G, Bassagasteguy L, Carrau RL, Mataza JC, Kassam A, Snyderman $\mathrm{CH}$ el al. A novel reconstructive technique after endoscopic expanded endonasal approaches: vascular pedicle nasoseptal flap. Laryngoscope. 2006;116(10):1882-6. doi:10.1097/01.mlg.0000234933.37779.e4

7. Stamm AC, Pignatari S, Vellutini E, Harvey RJ, Nogueira JF Jr. A novel approach allowing binostril work to the sphenoid sinus. Otolaryngol Head Neck Surg. 2008;138(4):531-2. doi:10.1016/j.otohns.2007.11.031

8. Beer-Furlan A, Evins Al, Rigante L, Burrell JC, Anichini G, Stieg PE et al. Endoscopic extradural anterior clinoidectomy and optic nerve decompression through a pterional port. J Clin Neurosci. 2014;21(5):836-40. doi:10.1016/j.jocn.2013.10.006

9. Kulwin C, Tubbs RS, Cohen-Gadol AA. Anterior clinoidectomy: description of an alternative hybrid method and a review of the current techniques with an emphasis on complication avoidance. Surg Neurol Int. 2011;2(1):140. doi:10.4103/2152-7806.85981
10. Giannotta SL.. Ophthalmic segment aneurysm surgery. Neurosurgery. 2002;50(3):558-62.

11. Hadeishi H, Suzuki A, Yasui N, Satou Y. Anterior clinoidectomy and opening of the internal auditory canal using an ultrasonic bone curette. Neurosurgery. 2003;52(4):867-70. doi:10.1227/01.NEU.0000053147.67715.58

12. Hayashi N, Masuoka T, Tomita T, Sato H, Ohtani O, Endo S. Surgical anatomy and efficient modification of procedures for selective extradural anterior clinoidectomy. Minim Invasive Neurosurg. 2004;47(6):355-8. doi:10.1055/s-2004-830121

13. Noguchi A, Balasingam V, Shiokawa Y, McMenomey SO, Delashaw JB Jr. Extradural anterior clinoidectomy. Technical note. J Neurosurg. 2005;102(5):945-50. doi:10.3171/jns.2005.102.5.0945

14. Takahashi JA, Kawarazaki A, Hashimoto N. Intradural en-bloc removal of the anterior clinoid process. Acta Neurochir (Wien). 2004;146(5):505-9. doi:10.1007/s00701-004-0249-9

15. Yonekawa Y, Ogata N, Imhof HG, Olivecrona M, Strommer K, Kwak TE et al. Selective extradural anterior clinoidectomy for supra- and parasellar processes. Technical note. J Neurosurg. 1997;87(4):636-42. doi:10.3171/jns.1997.87.4.0636

16. Ota N, Tanikawa R, Miyazaki T, Miyata S, Oda J, Noda Ket al. Surgical microanatomy of the anterior clinoid process for paraclinoid aneurysm surgery and efficient modification of extradural anterior clinoidectomy. World Neurosurg. 2015;83(4):635-43. doi:10.1016/j.wneu.2014.12.014

17. Matano F, Tanikawa R, Kamiyama H, Ota N, Tsuboi T, Noda Ket al. Surgical treatment of 127 paraclinoid aneurysms with multifarious strategy: factors related with outcome. World Neurosurg. 2016;85:169-76. doi:10.1016/j.wneu.2015.08.068

18. Kelley TF, Stankiewicz JA, Chow JM, Origitano TC, Shea J. Endoscopic closure of postsurgical anterior cranial fossa cerebrospinal fluid leaks. Neurosurgery. 1996;39(4):743-6. doi:10.1097/00006123-199610000-00019

19. White DR, Dubin MG, Senior BA. Endoscopic repair of cerebrospinal fluid leaks after neurosurgical procedures. Am J Otolaryngol. 2003;24(4):213-6. doi:10.1016/S0196-0709(03)00031-0 